\title{
Continual Professional Development (CPD): Improving Quality of Nursing Care in Nepal
}

\author{
Bibha Simkhada ${ }^{2,3,4^{*}}$, Sean Mackay ${ }^{2}$, Rose Khatri ${ }^{1}$, Chandra Kala Sharma ${ }^{7,8}$, Tara Pokhrel ${ }^{9}$, Sujan Marahatta ${ }^{1,5}$, \\ Catherine Angell ${ }^{4}$, Edwin van Teijlingen ${ }^{4,5,6}$, Padam Simkhada ${ }^{1,4,5}$ \\ ${ }^{1}$ Public Health Institute, Liverpool John Moores University, UK ${ }^{2}$ School of Nursing and Allied Health, Liverpool John Moores University, UK ${ }^{3}$ Wirral University \\ Teaching Hospital (WUTH) NHS Foundation Trust, UK ${ }^{4}$ Faculty of Health and Social Sciences, Bournemouth University, UK ${ }^{5}$ Manmohan Memorial Institute of \\ Health Sciences and Teaching Hospital, Nepal ${ }^{6}$ Nobel College, Pokhara University, Nepal ${ }^{7}$ Nepal Nursing Council (NNC), Kathmandu, Nepal ${ }^{8}$ Institute of Medicine, \\ Nursing Campus Maharajjung, TU, Kathmandu, Nepal ${ }^{9}$ Nursing Association of Nepal (NAN), Kathmandu, Nepal
}

\section{Introduction}

The notion that health professionals should be accountable to people and the society they serve is not a new concept (1). Globally, health professionals are being nudged to demonstrate their commitment with continuing professional development (CPD) in order to maintain competence in light of evidence-based practice and ever changing technology in health service provision. CPD provides an important strategy to improve the knowledge and skills of health practitioners as well as the quality of service (2). The World Health Organization also stresses the need to capacity enhancement of nurses and midwives through education, training and career development in Southeast Asia (3). The member states in the Region have agreed on a Decade for Strengthening Human Resources for Health in South-East Asia, 2015-2024, and country

Received:

25 March 2016

Revised:

16 August 2016

Accepted:

20 September 2016

\section{${ }^{\star}$ Correspondence: B.D.Simkhada@ljmu. ac.uk \\ School of Nursing and Al- lied Health, Liverpool John Moores University, UK} action plans have been developed to strengthen physicians, nurses and midwives with the focus on transforming education and retention (4).

This editorial highlights the importance of CPD and existing lack of such provision in the field of nursing in Nepal.

\section{CPD in Nursing}

In nursing and midwifery, CPD offers the opportunity to maintain, improve and broaden knowledge, expertise and develop their personal and professional qualities to enhance practice and career development (5). For example, in the UK (United Kingdom), nurses (and health visitors, midwives) are required to demonstrate their CPD in order to renew their registration. They must undertake a minimum of 35 hours of CPD in a three-year period, and link this to the professional code for nurses and midwives (6). The nurse also needs to collect five pieces of feedback, for example from service users or colleagues, and prepare five reflective accounts, for example based on the CPD completed, the feedback received, or on practice events. Nurses are then required to record a reflective discussion with another person on the register, and sign a declaration of their good health and good character. All of this evidence, along with confirmation of the minimum of 450 hours of practice in the three-year period, is submitted electronically to the UK's national overseeing body nursing and midwifery council (NMC), otherwise the registration lapses, and they are not allowed to practice. Similarly, in some developing countries nursing councils set requirements for the nurses to renew their registration. For example, the Delhi Nursing Council in India requires nurses to renew their registration once every five years with the achievement of 30 credit hours per year gained by means of attending continuing education programmes and workshops (7).

Nepal over the years has have limited process in ensuring CPD for nurses. The uptake of post-registration education and training (CPD) tends to be ad hoc (8). It seems to depend very much on what is made available by the government and/or INGOs (International Non-Governmental Organizations) rather than research or any other evidence. However, the Government of Nepal remains committed to universal health coverage and health service development, which is evident from the increase in budget, infrastructure development from central to the peripheral level with outreach facilities (9). Nurses are being recognized as the backbone of the Nepalese health system as they cover a much larger proportion of the population than doctors, particularly in rural areas (10). The delivery of quality health services and particularly in the remote areas remains a challenge and the health of the excluded and very poor populations has not improved as expected (10). Nurses and midwifes can be valuable assets for the service expansion in remote and rural areas of country, however lesson needs to be learnt from the UK and Australia where nurses has been important component of rural and remote health. In high-income countries with large rural areas nurses are often the first-line care providers in rural communities. In both the UK and Australia midwifery and nursing are different professionals with different qualifications, also may have both qualifications.

In Nepal nurses can continue to practise without any post registration training or any CPD and there is no any requirement to re-register if they have taken time out. There is no requirement for post-registration 
training or CPD for nurses to enhance and improve nursing skills in the Nepalese health system (9), despite the existence of a professional body, Nepal Nursing Council (NNC) to regulate in nursing registration. Recently the Nepal Nursing Council (NNC) called for the need for CPD in nursing to improve quality of care in Nepal. A recent literature highlighted that the nursing education is deteriorating due to commercialisation (11). Perhaps with the rise of commercialisation, now it is the time to raise the standard of nursing practice in Nepal through the introduction of compulsory further education in the form of a minimum standard of CPD. How CPD helps Nepali nurses to gain higher professional competence needs further discussion.

\section{Nursing education in Nepal}

There is long history of nursing in Nepal. The first School of Nursing was established in 1956 in Lalitpur Nepal (12). Currently there are around 250 nursing colleges in Nepal which offer different levels of nursing training from basic to masters' level (Table 1). The NNC board estimates there are about 40 colleges running Post-Basic Bachelor Nursing programmes, 54 running a BSc Nursing, 107 offering Proficiency Certificate Level in Nursing, 50 running Auxiliary Nurse Midwives (ANM) programmes and only five offering a Master in Nursing (MN) programmes. Around 5,000 nurses graduate annually and there are currently 33,692 nurses registered with the NNC with a further 24,919 registered AMN (13).

\begin{tabular}{|llll|}
\hline Table 1: Different types of nursing training in Nepal & & \\
\hline Title of the nurses & Programme/Degrees & $\begin{array}{l}\text { Training } \\
\text { duration }\end{array}$ & Entry requirements \\
\hline Auxiliary Nurse Midwife (ANM) & Auxiliary Nurse & 18 months & $\begin{array}{l}\text { pre and post School Leaving Certifi- } \\
\text { cate (SLC) }\end{array}$ \\
Staff nurse & $\begin{array}{l}\text { Proficiency Certificate Level in } \\
\text { Nursing (PCLN) }\end{array}$ & Three years & School-Leaving Certificate (SLC) \\
Staff nurse & $\begin{array}{l}\text { Post Basic Bachelor Nursing } \\
\text { (PBN) }\end{array}$ & Two years & $\begin{array}{l}\text { Two years post registration after } \\
\text { Bachelor of Nursing Science } \\
\text { Staff Nurse (specialisation) }\end{array}$ \\
& Three years & $\begin{array}{l}\text { Three years or more post registration } \\
\text { experience }\end{array}$ \\
\hline
\end{tabular}

\section{Future collaboration in CPD in nursing in Nepal}

Liverpool John Moores University, in collaboration with Bournemouth University, Manmohan Memorial Institute of Health Sciences (MMIHS) and Nepal Nursing Council is planning to conduct an in-depth situational analysis and needs assessment of CPD in nursing in Nepal. The study aims to assess the status of post-qualification training among nurses in Nepal. The findings from this study will provide the first ever overview of CPD training needs for nurses in Nepal. This study brings together a group of professionals from the UK and Nepal, with shared goal to improve pre and post registration nursing training in Nepal. Our study specially aims to:

i) quantify the uptake of post-registration training of registered nurses in Nepal

ii) assess the views of nurses and stakeholders including professional bodies such as the NNC, etc. on the need for and opportunities for post registration CPD for nurses and

iii) support NNC to establish CPD in nursing and the requirement for updated training in nursing re-registration process.

The study will use a mixed-methods approach comprising qualitative and quantitative methods (14). The survey comprise a sample of 500 currently working registered staff nurses or higher nursing qualification with minimum three years post registration experiences. The qualitative element comprises in-depth interviews with approximately 15-20 stakeholders (including nurse managers, nursing council board members, hospital matrons, nursing lecturers, and nursing education quality monitoring officers) from different health institutions and professional councils/bodies from across Nepal.

This project will hopefully be the start of a process of intelligence gathering around what types of CPD would be most costeffective and relevant to qualified nurses in Nepal and also around questions such as: "What are the best ways to deliver and evaluate CPD through schools of Nursing?" and "How best to monitor the quality of CPD and competencies of individual nurses by the NNC and NAN".

\section{Way forwards}

CPD is continually neglected, whereas there are promising signs recently. Recently, Nepal Nursing Council has started collaboration with Nepal Nursing Association and UK universities who has long history of providing pre and post registration nursing training to improve the quality of nursing care through the CPD. In order to improve the quality of nursing provision in Nepal and the standards of individual nurses we need to move to a system of post-registration with compulsory further learning and skills update. Nurses can be the backbone of community care in rural Nepal, especially in areas where there is no doctor available. In a modern health service we must ensure that our staff, in this case nurses and midwives stay up-to-date with the latest health knowledge and the most appropriate skills. We believe that the introduction of CPD will be beneficial to all nurses in Nepal. We are confident that it will produce 
more competent nurses and address the issues of low job satisfaction among nurses. It will also help to improve nurse's interpersonal relationships with multidisciplinary team, patients and family for better quality of care.

\section{References}

1. Brinkerhoff D. 2003. Accountability and Health Systems: Overview, Framework, and Strategies. Bethesda, MD: The Partners for Health Reformplus, Abt Associates Inc. Available in [http://www.who.int/management/partnerships/accountability/AccountabilityHealthSystemsOverview.pdf]. Accessed Feb 2016.

2. Guardini I, Talamini R, Fiorillo F, Lirutti M and Palese A. 2008. The effectiveness of continuing education in postoperative pain management: results from a followup study. The Journal of Continuous Education in Nursing. Vol. 39(6): pp. 281-288.

3. WHO. 2010. Nursing and Midwifery Services: Strategic Directions 2011-2015. Available in [http://apps.who.int/iris/bitstream/10665/70526/1/WHO_HRH_ HPN_10.1_eng.pdf]. Accessed on 09/03/2016.

4. WHO. 2016. WHO Progress Report on Nursing and Midwifery, 2013-2015. Available in [http://www.who.int/hrh/nursing_midwifery/nursing-midwifery_report_13-15.pdf?ua=1]. Accessed on 09/03/2016.

5. NMBA .2015. Fact sheet: Continuing professional development. Nursing and Midwifery Board of Australia. Available in [http://www.nursingmidwiferyboard.gov. au/Codes-Guidelines-Statements/FAQ/CPD-FAQ-for-nurses-and-midwives.aspx]. Accessed on Feb 2016.

6. NMC UK. 2016. Revalidation: What you need to do. Available in [http://revalidation.nmc.org.uk/ what-you-need-to-do]. Accessed on 08/03/2016. Nursing Midwifery Council UK.

7. Delhi Nursing Council. 2016. Registration Renewal Procedure. Available in [http://delhinursingcouncil.com/Registration-Renewal-Procedure.asp] Accessed on Feb 2016.

8. Adhikari R and Melia K. 2013. The (mis)management of migrant nurses in the UK: A sociological study. Journal of Nursing Management. Vol. 23(3): pp 1-29.

9. WHO. 2015. Success factors for women's and children's health: Nepal. Ministry of Health and Population Nepal, Partnership for Maternal, Newborn \& Child Health, WHO, World Bank and Alliance for Health Policy and Systems Research. Available in [http://www.who.int/pmnch/knowledge/publications/nepal_country_report. pdf?ua=1]. Accessed Jan 2016.

10. MoHP and NHSSP. 2012. Human Resources for Health Strategic Plan 2011-2015 Draft, 2030 Ministry of health and Nepal Health sector Support program, Available in [http://www.who.int/workforcealliance/countries/Nepal_HRHStrategicPlan_finaldraft.pdf]. Accessed on 14/01/2016.

11. Subedi DR. 2014. Growth of nursing education sector and its effects on professionalization of nurses in Nepal. Journal of Nursing and Health Science. Vol.3(4):pp. 34-39

12. Sigdel R. 2011. Nursing Education in Nepal: Historical Perspective. Health Prospect. Vol. 10: PP 89-90. Available in [http://www.nepjol.info/nepal/index.php/ HPROSPECT/article/view/5670/ 4667].Accessed Feb 2016.

13. Nepal Nursing Council. 2016. Current Registration Status Up to 10 Jan 2016. Available in [http://www.nnc.org.np/]. Accessed Feb 2016.

14. MacKenzieBryers H, van Teijlingen E andPitchforth E. 2014. Advocating mixed-methods approaches in health research.Nepal Journal of Epidemiology.Vol. 4(5): pp. 417-422. Available in [http://www.nepjol.info/index.php/NJE/article/view/12018/9768]. Accessed on June 2016. 